\title{
THE EFFECT OF WETTING ON THE COURSE OF THE DRUM GRANULATION
}

\author{
Michał Błaszczyk ${ }^{1}$, Andrzej Heim² ${ }^{2}$ Tomasz P. Olejnik ${ }^{* 3}$ \\ ${ }^{1}$ Lodz University of Technology, The Institute of Turbomachinery, ul. Wólczańska 219/223, 90-924 \\ Łódź, Poland \\ ${ }^{2}$ Lodz University of Technology, Department of Process Equipment, ul. Wólczańska 213, 90-924 \\ Łódź, Poland \\ ${ }^{3}$ Lodz University of Technology, The Institute of Food Technology and Analysis, ul. Stefanowskiego \\ 4/10, 90-924 Łódź, Poland
}

\begin{abstract}
This paper presents the results of experimental drum granulation of silica flour with the use of wetting liquids with different values of surface tension. Additionally, different liquid jet breakup and different residual moisture of the bed were applied in the tests. The process was conducted periodically in two stages: wetting and proper granulation, during which no liquid was supplied to the bed. The condition of the granulated material after the period of wetting (particle size distribution and moisture of separate fractions) and a change in the particle size distribution during the further conduct of the process (granulation kinetics) were determined.
\end{abstract}

Keywords: drum granulation, surface tension, particle size distribution

\section{INTRODUCTION}

The agglomerative non-pressure granulation of powders in the flowing layer of material despite some imperfections (the product is polydisperse (Obraniak and Gluba, 2008), and the mechanical strength of granules is lower in comparison to the granulation obtained in the pressure), is widely applied at the industrial scale. Its advantages include simplicity of the device design and low energy expenditures for conducting the process. Drum granulation is one of the ways to realize this granulation (Obraniak and Gluba, 2011; Obraniak and Gluba, 2012a). An important element of this way of agglomeration is wetting the bed by means of liquid which by creating the so-called liquid bridges enables to create bonds between the raw material particles (Hapgood et al. 2002; Nguyen et al. 2009). This phenomenon which has a significant effect on granulation and its course depends on the amount of the wetting liquid (Marín Rivera et al. 2017; Ramachandran Rohit et al. 2008; Smirani-Khayati et al. 2009) and its properties, i.e. viscosity and surface tension (Hotta et al., 1974; Opaliński, 2001; Pepin et al., 2000; Rajniak et al., 2007; Willet et al., 2003). However, previous theoretical analyses and experimental studies do not enable the unambiguous evaluation of the effect of the bed wetting conditions on the granulation process course.

During the selection of a binding agent, forces occurring during the collision of two spherical particles were analyzed theoretically (Ennis et al., 1990; Ennis et al., 1991). The authors introduced the Stokes number, the value of which is inversely proportional to the binding liquid viscosity and which does not depend on its surface tension, to describe the phenomenon. This theory was modified by Nienow (Nienow, 1995), demonstrating the need to take also surface tension of the liquid phase into account. 
He stated, based on experiments, that the surface tension has a greater effect on the granulation process than the liquid viscosity. Conclusions in both cases are more of qualitative than quantitative nature. Also the effect of non-ionic surfactants on the shape, size and strength of granules was examined (Junnila, 1988). A mixture of cellulose and corn starch was used as the study material, while aqueous solutions of polysorbate 80 were used to wet the bed. It was found that the addition of a surfactant causes a decrease in the number of fine granules with the simultaneous formation of excessively large granules. The meagerness of results of works concerning particularly the effect of liquid surface tension on the course of flow granulation justifies conducting further studies concerning this question.

\section{AIM OF THE STUDY}

The aim of the study was to examine the effect of the bed wetting conditions on the course of drum granulation, and in particular:

- surface tension of the wetting liquid,

- the diameter of drops of the wetting liquid,

- the residual moisture of the bed.

\subsection{Description of the research methodology}

Granulation trials were conducted in a drum granulator with the diameter of $0.6 \mathrm{~m}$ and length of $0.4 \mathrm{~m}$. The drum had 8 lengthwise dividers attached to its internal wall. The drum rotations in all trials were the same and were equal to $15 \mathrm{~s}^{-1}$. It corresponded to $0.275 n_{\text {critical }}$. Adopting such a value of the drum rotational speed enabled to obtain the desired, cascade motion of the material during the whole cycle of the process. The degree to which the drum was filled was also constant and was equal to $15 \%$.

Silica flour, whose granulometric composition is shown in Fig. 1, was used as the granulated material. The average dimension of flour particles was equal to $d_{32}^{(m)}=0.024 \mathrm{~mm}$, while density of loosely heaped bed $\rho_{l}=951 \mathrm{~kg} / \mathrm{m}^{3}$, and concentrated $\rho_{z}=1525 \mathrm{~kg} / \mathrm{m}^{3}$.

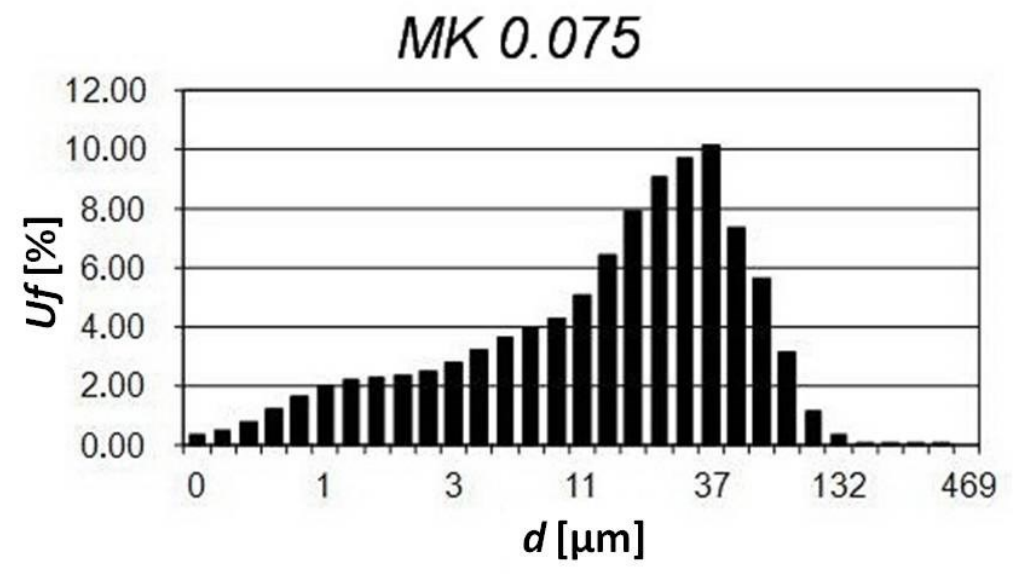

Fig. 1. Granulometric composition of silica flour used in the tests

Distilled water and aqueous solutions of polyoxyalkene glycol ether of lauryl alcohol, under the trade name of Rokanol L4P5, were used to wet the bed. The Rokanol concentration in separate trials was from $0.01 \%$ to $0.04 \%$, which caused a significant decrease in the liquid surface tension, and at the same time small changes in viscosity. Properties of solutions used are shown in Table 1. 
Table 1. Properties of used wetting liquids

\begin{tabular}{|c|c|c|c|c|c|}
\hline & Water & $0.01 \%$ & $0.02 \%$ & $0.03 \%$ & $0.04 \%$ \\
\hline Surface tension, $\gamma \times 10^{3}[\mathrm{~N} / \mathrm{m}]$ & 71.97 & 54.79 & 42.40 & 37.61 & 35.04 \\
\hline Viscosity at $25^{\circ} \mathrm{C} \eta \times 10^{3}[\mathrm{~Pa} \mathrm{~s}]$ & 0.898 & 0.880 & 0.864 & 0.846 & 0.820 \\
\hline
\end{tabular}

Wetting parameters were established experimentally based on the initial tests. The wetting liquid was sprayed using a Spraying System Deutschland GmbH pneumatic nozzle with 2050 head. The highest mono-dispersion of the drops jet was obtained at the liquid flow rate of $0.006 \mathrm{~m}^{3} / \mathrm{h}$ and air flow rates between 1.25 and $2 \mathrm{~m}^{3} / \mathrm{h}$. Four air flow rates were used and the obtained average dimensions of drops $d_{32}^{(k)}$ are shown in Table 2 .

Table 2. Sauter mean diameters of the sprayed liquid drops

\begin{tabular}{|c|c|c|c|c|}
\hline$Q_{\text {air }}\left[\mathrm{m}^{3} / \mathrm{h}\right]$ & 1.25 & 1.50 & 1.75 & 2.00 \\
\hline$d_{32}^{(k)}[\mu \mathrm{m}]$ & 23.22 & 20.24 & 14.85 & 13.13 \\
\hline
\end{tabular}

From the initial tests, it was determined that for dry silica flour, moisture enabling to conduct the granulation process is contained in the range from 0.19 to $0.21 \mathrm{~g}$ liquid/g dry matter of the powder. Below this limit value, granulation does not occur, forming only nuclei of nucleation in the bed, without the possibility of their growth to the size of granules. However, after exceeding the upper limit value of moisture, the over-wetted material sticks to the granulator walls. 4 values of moisture were selected for testing: $0.190 ; 0.195 ; 0.200$ and $0.205 \mathrm{~g}$ liquid/g dry matter of the powder, respectively.

The granulation process was conducted in the periodic way in two stages: wetting of the bed and the proper granulation, without supplying the liquid to the granulated material. This imitated the continuous process, during which, in the initial section of the drum, flowing and moving material is wetted, while in the next section only shaping of the product occurs. At the constant liquid flow rate, times of the first stage (wetting) differed from each other and in boundary cases were equal to $841 \mathrm{~s}$ and $974 \mathrm{~s}$, respectively.

Following the end of wetting, a sample was taken and its particle size distribution and values of moisture of separate fractions were determined. During the second stage of the process, in which the liquid was not supplied to the bed, samples of the granulated material were taken after 240, 480,960, 1440 and $1920 \mathrm{~s}$, respectively when the process was interrupted, because the phenomenon of sticking the granulated material to the drum occurred. For separate times of granulation, particle size distribution of the granulated material was determined.

\section{RESULTS}

\subsection{The wetting stage}

Based on the sieve analysis results of the material samples taken following the wetting, a significant share of the non-granulated material was determined in all granulation samples. The material which passed through a sieve with a mesh size of $1 \mathrm{~mm}$ was considered the non-granulated material. The share of this non-granulated part of the material as well as the particle size distribution of the granules obtained after the wetting, depended significantly on the bed wetting conditions. Examples of this are shown in Figs. 2, 3 and 4. The dependence character for different parameter sets is similar in all cases. 


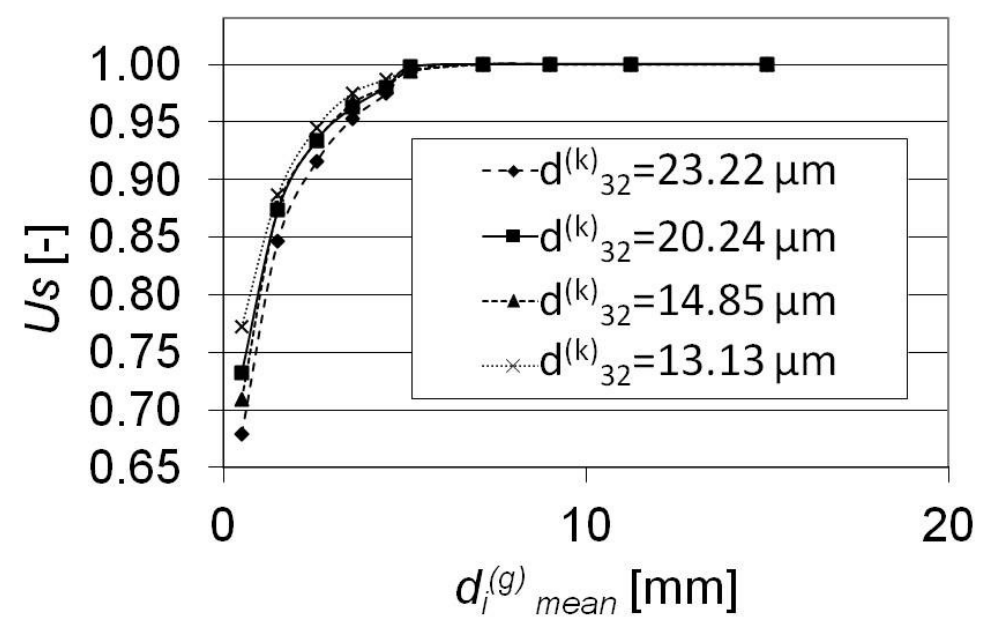

Fig. 2. The exemplary comparison of granulometric compositions of the bed after the wetting stage obtained for different degrees of the wetting liquid jet breakup, for $\gamma=35.04 \cdot 10^{-3} \mathrm{~N} / \mathrm{m}$ and $w=0.2 \mathrm{~g}$ liquid/g dry matter

The effect of wetting liquid drops size is shown in Fig. 2. It indicates that along with the increase in the dimension of drops, the share of the non-granulated material decreases. The increase in the wetting liquid drop diameter, which results in the increase in the weight of the liquid, enhanced the probability of local overwetting in the bed, which in turn meant creating kernel of granule. The wetting liquid surface tension has a significantly smaller effect (Fig. 3). In this case, the amount of the non-granulated material increases along with a decrease in the value of this parameter, which is probably the result of lowering of the mechanical durability of granules and their disintegration during circular movement.



Fig. 3. The exemplary comparison of granulometric compositions of the bed after the wetting stage obtained using liquids with different values of surface tension, for diameters of drops $d_{32}^{(k)}=20.24 \mu \mathrm{m}$ and moisture content $w=0.19 \mathrm{~g}$ liquid/g dry matter

However, the amount of the non-granulated material after the period of wetting depends essentially on the residual moisture of the bed (Fig. 4). An increase in this moisture means better kernel yielding and an increase in the number of liquid bonds between the material grains, which in consequence significantly decreases the amount of the non-granulated material. For the most beneficial set of parameters in this regard $\left(d_{32}^{(k)}=23.22 \mu \mathrm{m}, \gamma=71.97 \cdot 10^{-3} \mathrm{~N} / \mathrm{m}\right.$ and $w=0.205 \mathrm{~g}$ liquid $/ \mathrm{g}$ dry matter $)$, the smallest amount of the non-granulated material equal to $62 \%$ by weight was obtained after the period of wetting. 


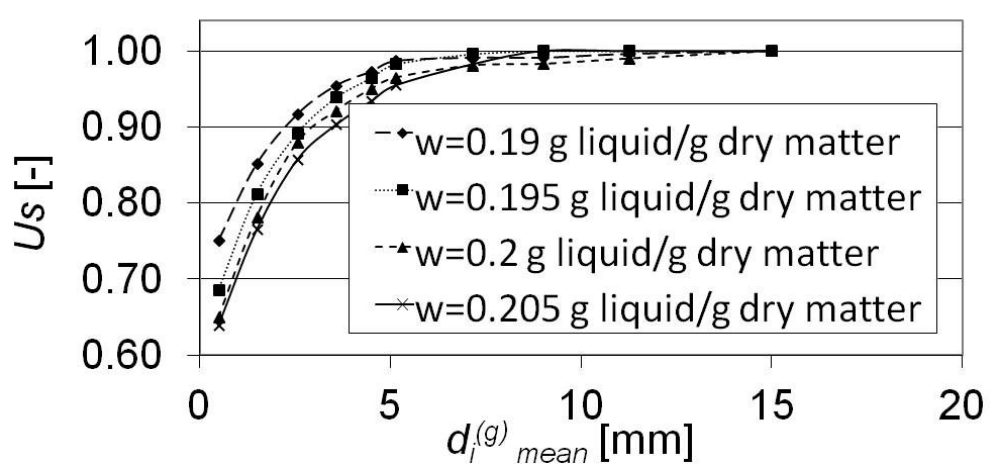

Fig. 4. The exemplary comparison of the granulometric compositions of the bed after the wetting stage obtained for different values of residual moisture, at $d_{32}^{(k)}=23.22 \mu \mathrm{m}$ and $\gamma=54.79 \cdot 10^{-3} \mathrm{~N} / \mathrm{m}$

Also the moisture distribution in granules from separate size fractions was examined and it was determined that this distribution is different during the application of the wetting liquid with a different value of surface tension. In all cases in the smallest granules (up to about $5 \mathrm{~mm}$ ) along with an increase in the granules dimensions, their moisture increased, while for large granules (over $5 \mathrm{~mm}$ ), this dependence was different during the application of liquids differing in the value of surface tension. For clear water, a further increase in moisture with an increase in granules dimensions occurred, while for the solution with the lowest value of surface tension, a clear decrease in moisture in granules with larger dimensions was observed. During the application of liquid with intermediate values of surface tension, results within these boundaries were obtained. Exemplary results for one of the trials are shown in Fig. 5.

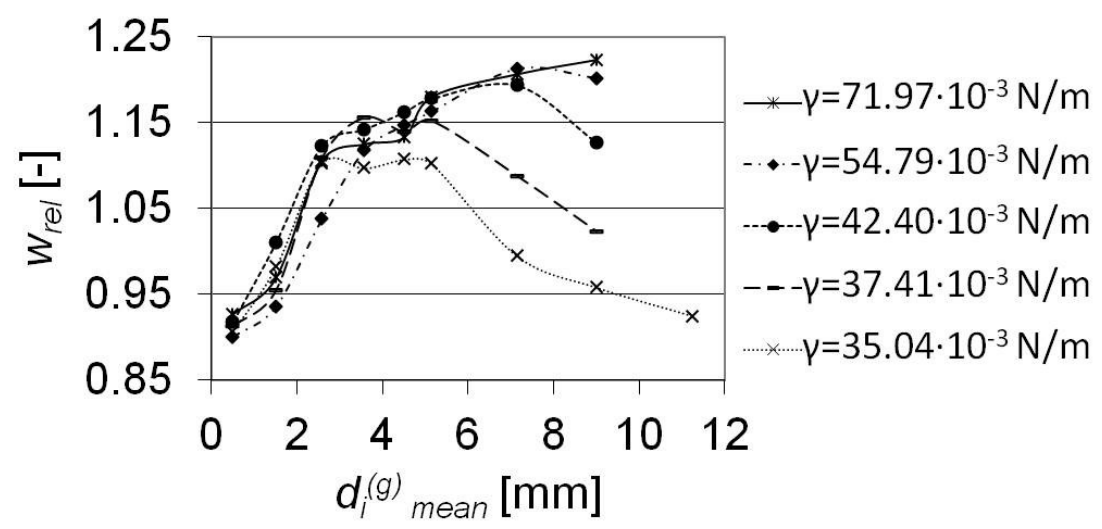

Fig. 5. The comparison of relative moisture values of separate fractions of the bed for different values of the wetting liquid surface tension $\left(d_{32}^{(k)}=13.13 \mu \mathrm{m} ; w=0.2 \mathrm{~g}\right.$ liquid/g dry matter)

The presented results indicate that a decrease in the wetting liquid surface tension facilitates its penetration to the layer of the granulated material, which intensifies the initial agglomeration process. At the lowest value of the liquid surface tension, particles of the primary material are attached to larger agglomerates more intensively, which causes a decrease in the relative moisture of these large granules.

\subsection{The stage of proper granulation}

During the second stage, the following phenomena occur simultaneously (Heim et al., 2000; Iveson et al. 2001; Obraniak and Gluba, 2012b; Sastry and Fuerstenu, 1973):

- multiple layers of the non-granulated material on the granules formed in the first stage,

- smaller granules' bonding, 
- wearing of the primary material particles (separating from the granules' surface),

- breakup of granules with the insufficient strength,

- increase in the granule strength as a result of their consolidation.

However, it is assumed that due to the lack of wetting the bed from the primary material (single particles), new nuclei of granules are not formed, and thus the mechanism of enucleation does not occur. The mechanisms enumerated above cause a change in the particle size distribution of the processed material and an increase in the average dimension of particles. As was determined, three wetting parameters changed in tests have a different effect on the process kinetics. This is shown in exemplary Figs. 6, 7 and 8. It follows from them that this kinetics in terms of time used in the tests can be approximated by a straight line obtaining high values of correlation coefficient $R^{2}$. It must be underlined once more that limiting this time resulted from the phenomenon of sticking the material to the granulator walls (liquid was squeezed from the inside of granules to their surface). Consequently, the granulation kinetics in its second stage is described by the equation

$$
d_{\text {avg }}^{(g)}=A \cdot t+B
$$

in which constant value $B$ is characteristic of the bed condition after wetting, while constant $A$ indicates the rate of the average granule dimension increase during the proper granulation.



Fig. 6. The exemplary comparison of the rate of the average granule diameter increase for different values of residual moisture of the bed $\left(d_{32}^{(k)}=13.13 \mu \mathrm{m} ; \gamma=71.97 \cdot 10^{-3} \mathrm{~N} / \mathrm{m}\right)$

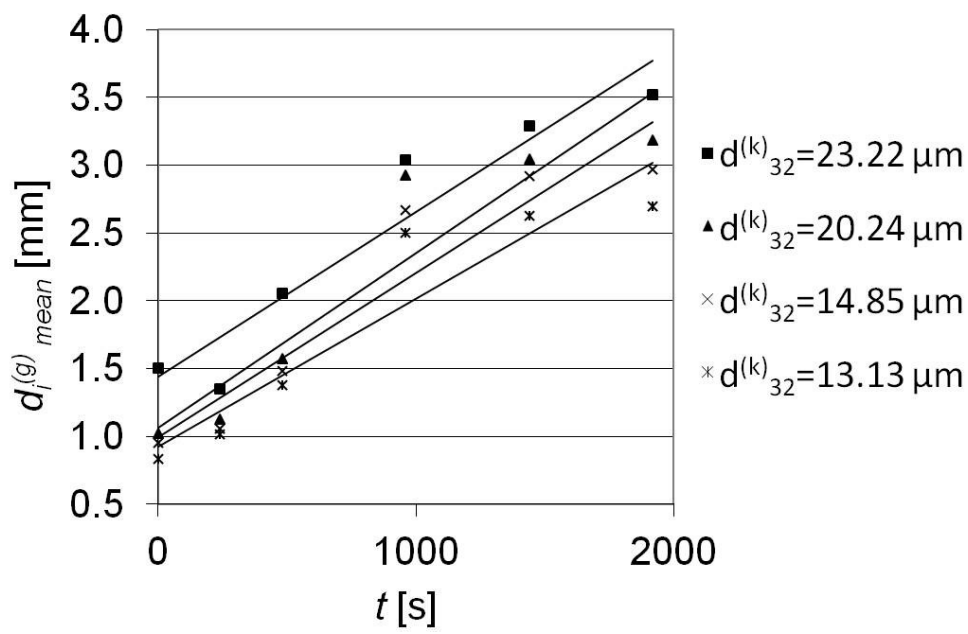

Fig. 7. The exemplary comparison of the average granule diameter increase rate for different degrees of the liquid jet breakup $\left(w=0.19 \mathrm{~g}\right.$ liquid $/ \mathrm{g}$ dry matter; $\gamma=35.04 \cdot 10^{-3} \mathrm{~N} / \mathrm{m}$ ) 
The increase in the bed moisture as indicated in Fig. 6, makes the average dimension of particles after wetting (at the beginning of the proper granulation stage) be greater (a higher degree of the material agglomeration). The granulation rate in this second period is also greater. However, the degree of partitioning of the liquid jet, that is the size of drops, has a very small effect on the process kinetics during the proper granulation (Fig. 7). And although the final product differs in separate trials performed at different liquid partitioning, it is the result of the previous formation of particles during wetting.

A change in the wetting liquid surface tension from about $72 \cdot 10^{-3} \mathrm{~N} / \mathrm{m}$, to about $55 \cdot 10^{-3} \mathrm{~N} / \mathrm{m}$, causes significant changes in the granulation rate (Fig. 8). The value of constant $A$ decreases then from 0.002 to 0.0013 , but further decreasing the liquid surface tension does not cause practically any change in this rate.

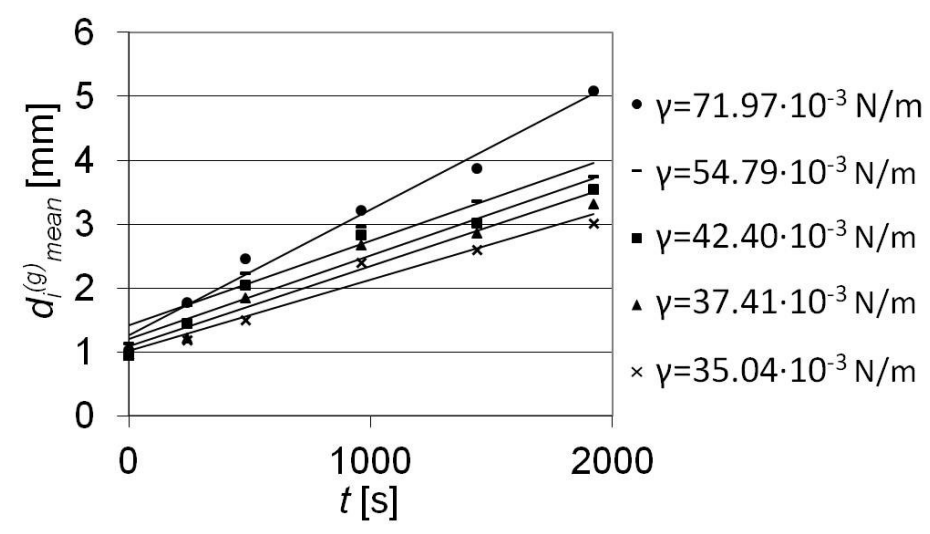

Fig. 8. The exemplary comparison of the average granule diameter increase for different values of the wetting liquid surface tension $\left(w=0.2 \mathrm{~g}\right.$ liquid/g dry matter; $\left.d_{32}^{(k)}=13.13 \mu \mathrm{m}\right)$

\subsection{The description of granulation product particle size distribution}

Equation (1), in which coefficients $A$ and $B$ are dependent on bed wetting conditions, is used to describe granulated material particle size distribution. The results of tests enabled to determine the detailed form of these dependencies.

$$
\begin{aligned}
& A=\left(\frac{\Delta d_{32}^{(g)}}{t}\right)_{\mathrm{o}}\left[10^{-2.8}\left(\frac{w}{w_{\mathrm{o}}}\right)^{0.68}\left(\frac{\gamma}{\gamma_{\mathrm{o}}}\right)^{0.29}\left(\frac{d_{32}^{(k)}}{\left.d_{32}^{(k)}\right)^{0.34}}\right]\right. \\
& B=d_{32}^{(m)}\left[10^{1.82}\left(\frac{w}{w_{\mathrm{o}}}\right)^{0.89}\left(\frac{\gamma}{\gamma_{\mathrm{o}}}\right)^{0.29}\left(\frac{d_{32}^{(k)}}{\left.d_{32}^{(k)}\right)^{0.34}}\right]\right.
\end{aligned}
$$

where $\left(\Delta d_{32}^{(g)} / t\right)_{0}$ is the rate of the average granule dimension increase using basic parameters which were equal to: $w_{o}=0.19 \mathrm{~g}$ liquid $/ \mathrm{g}$ dry matter; $d_{32 o}^{(k)}=13.13 \mu \mathrm{m} ; \gamma_{o}=35.04 \cdot 10^{-3} \mathrm{~N} / \mathrm{m}$.

As follows from Eqs. (2) and (3), the values of power exponents in expressions related to the size of the wetting liquid drops and surface tension of this liquid are in both cases the same, the final form of the dependence describing the process kinetics can be presented by the equation:

$$
d_{32}^{(g)}=\left[10^{-2.8}\left(\frac{d_{32}^{(g)}}{t}\right)_{\mathrm{o}}\left(\frac{w}{w_{\mathrm{o}}}\right)^{0.68} \cdot t+10^{1.82} d_{32}^{(m)}\left(\frac{w}{w_{\mathrm{o}}}\right)^{0.89}\right]\left[\left(\frac{\gamma}{\gamma_{\mathrm{o}}}\right)^{0.29}\left(\frac{d_{32}^{(k)}}{d_{32}^{(k)}}\right)^{0.34}\right]
$$

Correlation coefficient of the obtained dependence is $R^{2}=0.91$. 
From the practical point of view, not only the average dimension of particles, but also the dispersion of the granule size in the final product is of interest. They are different at different wetting conditions, as shown in Figs. 9, 10 and 11.



Fig. 9. The exemplary comparison of shares of separate particle sizes in the final product at different diameters of the wetting liquid drops $\left(w=0.19 \mathrm{~g}\right.$ liquid $/ \mathrm{g}$ dry matter; $\left.\gamma=71.97 \cdot 10^{-3} \mathrm{~N} / \mathrm{m}\right)$

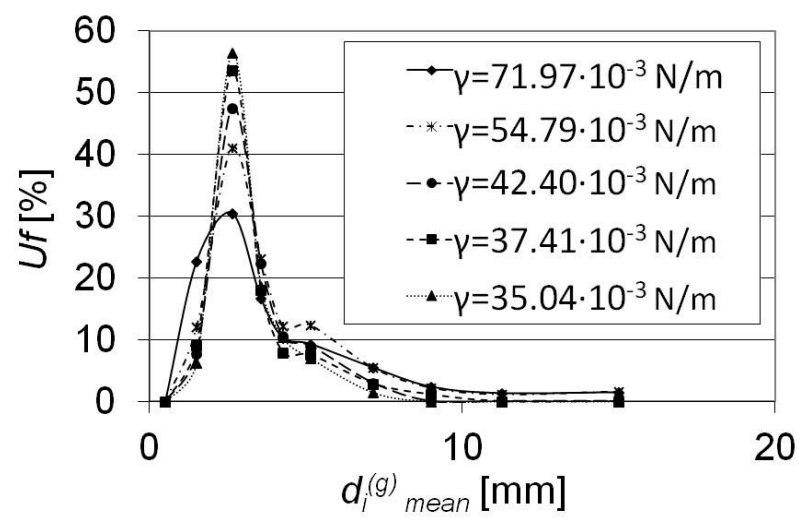

Fig. 10. The exemplary comparison of shares of separate particle sizes in the final product for different values of the liquid surface tension $\left(d_{32}^{(k)}=20.24 \mu \mathrm{m} ; w=0.19 \mathrm{~g}\right.$ liquid $/ \mathrm{g}$ dry matter $)$

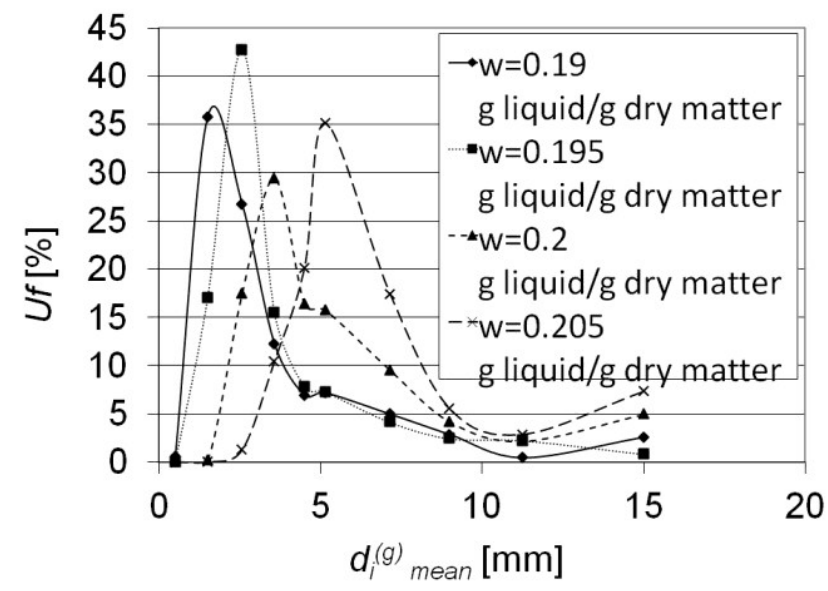

Fig. 11. The exemplary comparison of shares of separate particle sizes in the final product for different values of residual moisture of the bed $\left(d_{32}^{(k)}=13.13 \mu \mathrm{m} ; \gamma=71.97 \times 10^{-3} \mathrm{~N} / \mathrm{m}\right)$

For the mathematical description of these compositions, modified asymmetry coefficient $K_{1}$ and flattening coefficient $K_{2}$ calculated from the equations were used 


$$
\begin{aligned}
K_{1} & =\frac{M_{4}-\left(M_{2}\right)^{2}}{M_{4}} \\
K_{2} & =\frac{M_{3}}{M_{2}^{3 / 2}+\left|M_{3}\right|}
\end{aligned}
$$

where the central moment of order $k$ is determined by the formula

$$
\begin{gathered}
m_{1}=\sum_{i=1}^{n} x_{i}^{(g)} d_{i}^{(g)} \\
M_{k}=\sum_{i=1}^{n}\left(x_{i}^{(g)}-m_{i}\right)^{k} d_{i}^{(g)}
\end{gathered}
$$

and the zero moment of the first order

$$
m_{1}=\sum_{i=1}^{n} x_{i}^{(g)} d_{i}^{(g)}
$$

While analyzing the obtained results, a virtual absence of the effect of the liquid drop diameter and its surface tension on the asymmetry coefficient value was determined. In boundary cases, values differing by less than $10 \%$ were obtained. A change in the dimension of drops had also a very small effect on the flattening coefficient (a maximum of about 2\%). However, a significant effect of the liquid surface tension and the residual moisture of the bed on the value of the flattening coefficient were determined. It is shown as an example in Figs. 12 and 13.

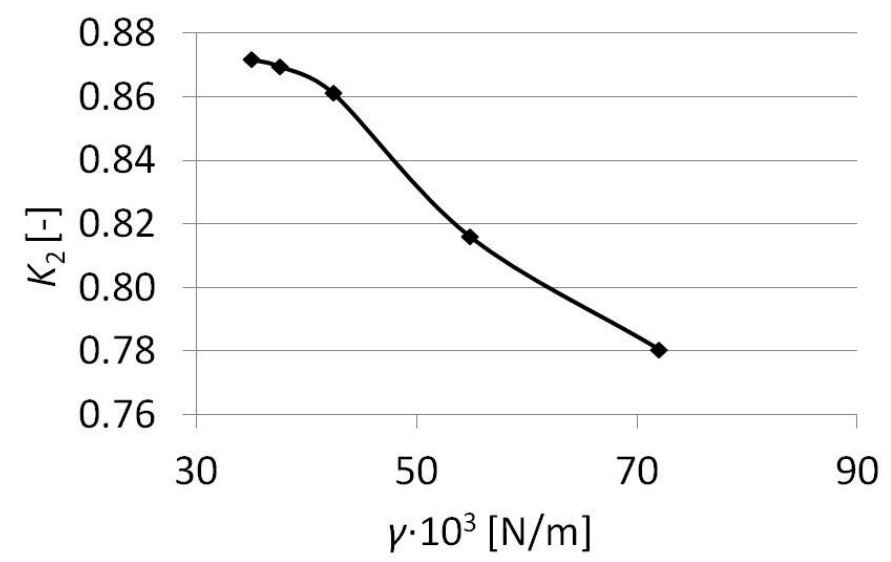

Fig. 12. The exemplary comparison of changes in flattening coefficient $K_{2}$ obtained for different values of the liquid surface tension $\left(d_{32}^{(k)}=20.24 \mu \mathrm{m} ; w=0.19 \mathrm{~g}\right.$ liquid $/ \mathrm{g}$ dry matter $)$

Also the residual moisture of the bed affects significantly the value of the asymmetry coefficient (Fig. 14). In the case of the liquid surface tension, as indicated by Fig. 12, its decrease causes an increase in the value of the coefficient, which indicates greater dimensional homogeneity of the granulation product. Granules created in these conditions are less mechanically durable, which in turn means a rise in the contribution of smaller granules. However, the effect of the residual moisture of the bed is more complex. An increase in this moisture from 0.19 to $0.195 \mathrm{~g}$ liquid/g dry matter results in an increase in the value of both the flattening coefficient and the asymmetry coefficient. Higher values of these coefficients indicate that the product is more monodisperse. However, further increasing the bed moisture leads to greater dispersion of the obtained granule size. This is caused by the fact that more moisturized granules which also achieve bigger final diameter are less prone to destructive mechanisms. Moreover, the excess moisture that is squeezed outside in the later stage of granulation causes binding of granules and building up of not yet granulated material creating big agglomerates. 


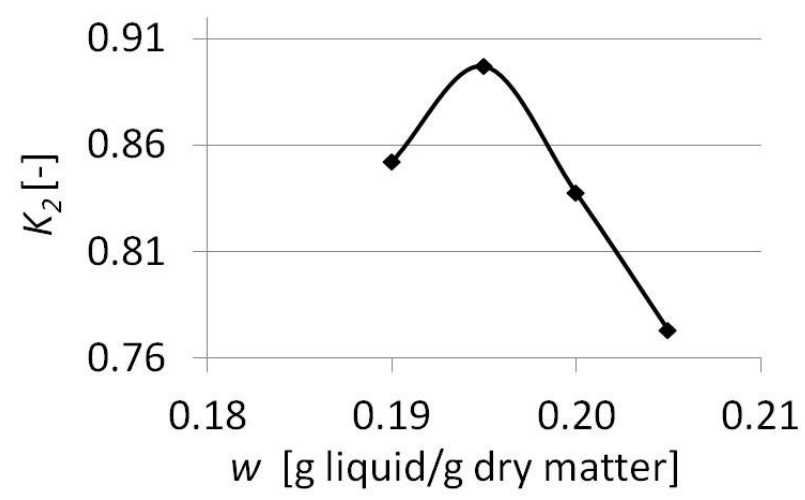

Fig. 13. The exemplary comparison of changes in flattening coefficient $K_{2}$ obtained for different values of the residual moisture of the product $\left(d_{32}^{(k)}=13.13 \mu \mathrm{m} ; \gamma=71.97 \cdot 10^{-3} \mathrm{~N} / \mathrm{m}\right)$

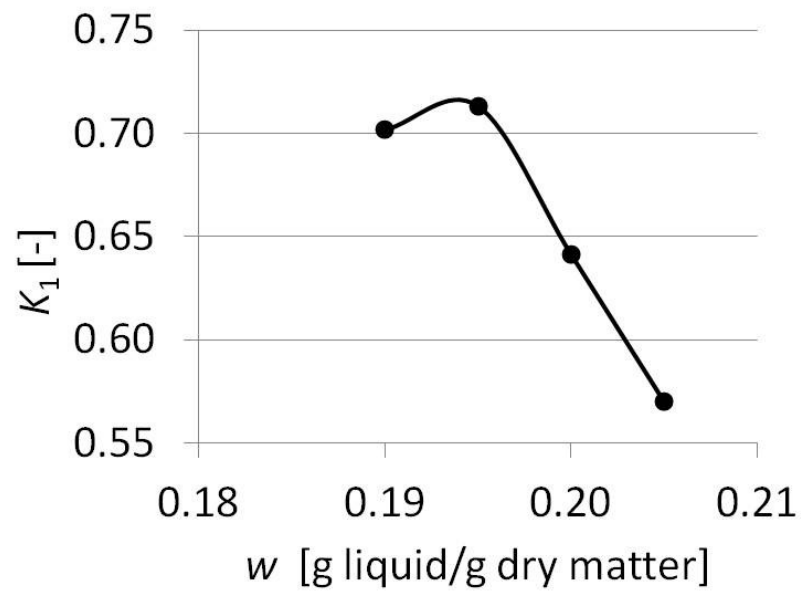

Fig. 14. The exemplary comparison of values of asymmetry coefficient $K_{1}$ for different values of the product moisture $\left(d_{32}^{(k)}=13.13 \mu \mathrm{m} ; \gamma=71.97 \cdot 10^{-3} \mathrm{~N} / \mathrm{m}\right)$

\section{CONCLUSIONS}

- The flow granulation process of silica flour is possible from the practical point of view using wetted beds within boundaries from 0.190 to $0.205 \mathrm{~g}$ of liquid/g dry matter. A similar limitation is set by the granulation time. When its critical value is exceeded, the material sticks to the drum walls.

- The process course both in the wetting stage and during the proper granulation is affected mostly by the bed moisture. The wetting liquid surface tension and the degree of its partitioning during wetting have a smaller effect and in both cases it is on the same level.

- The size composition of the final granulation product depends on the wetting conditions. It is affected to a different extent by the residual moisture, a degree of bonding liquid partitioning and its surface tension.

\section{SYMBOLS}
$A, B \quad$ constants, -
$K_{I} \quad$ modified asymmetry coefficient, -
$K_{2} \quad$ modified flattening coefficient, - 


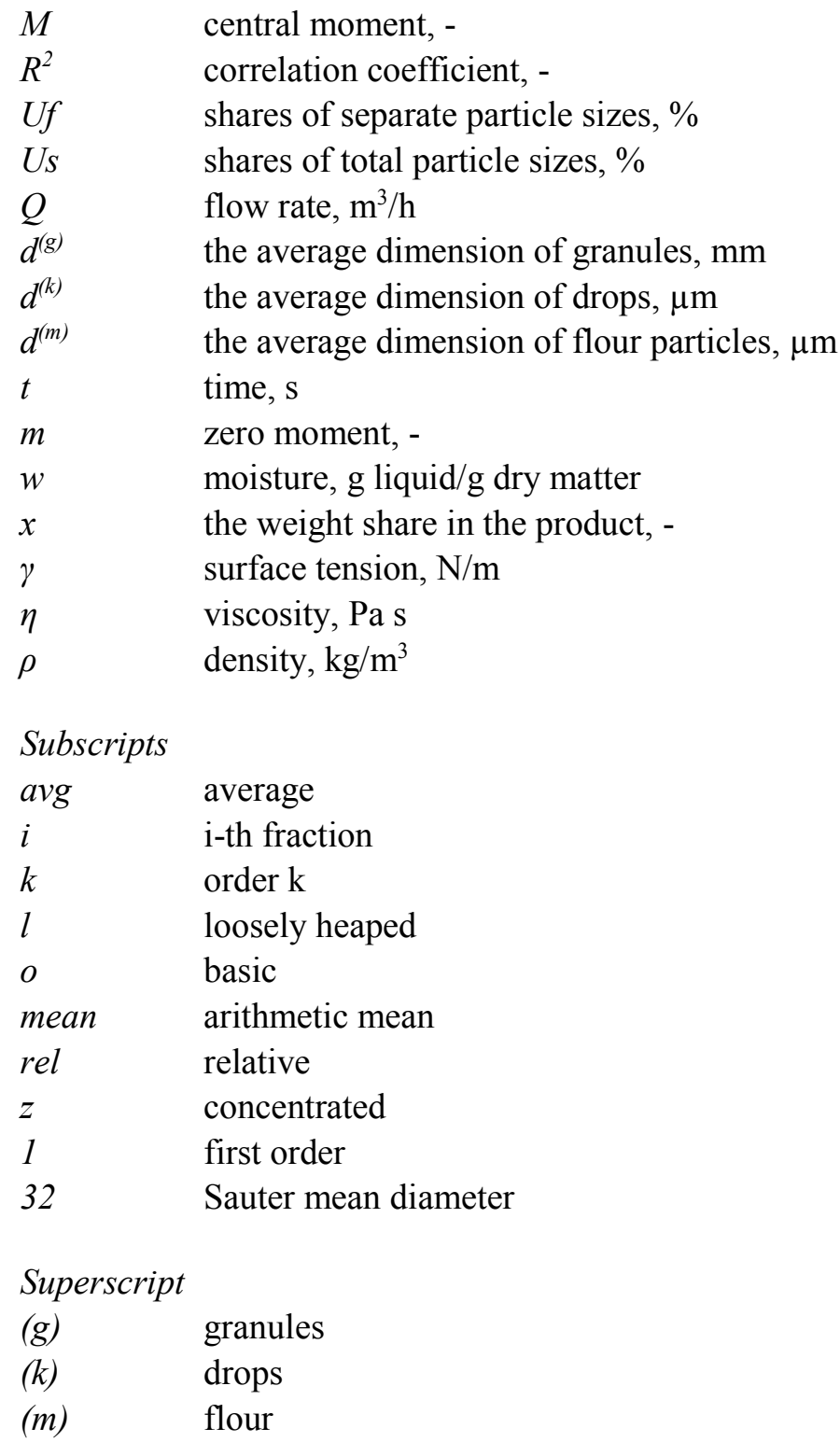

\section{REFERENCES}

Charles-Williams H.R., Wengeler R., Flore K., Feise H., Hounslow M.J., Salman A.D., 2011. Granule nucleation and growth: Competing drop spreading and infiltration processes. Powder Technol. 206, 63-71, DOI: 10.1016/j.powtec.2010.06.013.

Ennis B.B., Li J., Tardos G.I., Pfeffer R., 1990. The influence of viscosity on the strength of an axially strained pendular liquid bridge. Chem. Eng. Sci., 45, 3071-3088. DOI: 10.1016/0009-2509(90)80054-I.

Ennis B.B., Li J., Tardos G.I., Pfeffer R., 1991. A microlevel - based characterization of granulation phenomena. Powder Technol., 65, 257-272. DOI: 10.1016/0032-5910(91)80189-P.

Gluba T., Obraniak A., 2008. Ocena jednorodności produktu mokrej granulacji bębnowej. Przemyst Chemiczny, 87 (2), 125-128.

Hapgood K.P., Litster J.D., Biggs S.R., Howes T., 2002. Drop penetration into porous powder beds. J. Colloid Interface Sci., 253, 353-366. DOI: 10.1006/jcis.2002.8527.

Heim A., Gluba T., Obraniak A., 2000. The effect of process and equipment parameters on the drum granulation kinetics. Physicochemical Problems of Mineral Processing, 34, 67-76.

Hotta K., Takeda K., Iinoya K., 1974. The capillary bonding force of a liquid bridge. Powder Technol., 10, 231 236. DOI: 10.1016/0032-5910(74)85047-3. 
Iveson S.M., Litster J.D., Hapgood K., Ennis B.J., 2001. Nucleation, growth and breakage phenomena in agitated wet granulation processes. Powder Technol., 117, 3-39. DOI: 10.1016/S0032-5910(01)00313-8.

Junnila R., Heinamaki J., Yliruusi J., 1998. Effect of surface - active agent on the size, shape and hardness of micro - crystalline cellulose /maize starch pellets prepared by an extrusion - spheronization technique. S.T.P. Pharma Sciences, 8 (4), 221-226.

Nguyen T., Shen W., Hapgood K., 2009. Drop penetration time in heterogeneous powder beds. Chem. Eng. Sci., 64, 5210-5221. DOI: 10.1016/j.ces.2009.08.038.

Nienow A.W., 1995. Fluidised bed granulation and coating application to materials agriculture and biotechnology. Chem. Eng. Comm., 139, 233-253. DOI: 10.1080/00986449508936406.

Obraniak A., Gluba T., 2011. A model of granule porosity changes during drum granulation. Physicochemical Problems of Mineral Processing, 46, 219-228.

Obraniak A.. Gluba T., 2012a. A model of agglomerate formation during disc granulation process. Chem. Process Eng., 33,1,153-165. DOI: 10.2478/v10176-012-0014-1.

Obraniak A., Gluba T., 2012b. Model of energy consumption in the range of nucleation and granule growth in drum granulation bentonite. Physicochemical Problems of Mineral Processing, 48, 1, 121-128.

Opaliński I., 2001. Siły adhezji kapilarnej w materiałach rozdrobnionych. Mechanizm oddziaływania i modelowanie. Inż. Chem. Proc., 22, 99-108.

Pepin X., Sossetti D., Simons S.J.R., 2000. Modeling pendular liquid bridges with a reducing solid liquid interface. J. Coll. Int. Sci., 232, 298-308. DOI: 10.1016/S0032-5910(02)00235-8.

Rajniak P., Mancinelli C., Chern R.T., Stepanek F., Farber L., Hill B.T., 2007. Experimental study of wet granulation in fluidized bed: Impact of the binder properties on the granule morphology. Int. J. Pharm., 334, 92-102. DOI: 10.1016/j.ijpharm.2006.10.040.

Ramachandran R.P., Sanders J.M.-H., Constantijn F.W., Glaser Th., Immanuel Ch.D., Doyle III F.J.; Litster J.D., Stepanek F., Wang Fu-Yang, Cameron I.T., 2008. Experimental studies on distributions of granule size, binder content and porosity in batch drum granulation: Inferences on process modelling requirements and process sensitivities. Powder Technol. 188, 89-101. DOI: 10.1016/j.powtec.2008.04.013.

Rivera M.R., Koltsov A., Araya Lazcano B., Douce J.-F., 2017. Wettability in water/iron ore powder systems: To the universality of the Cassie model. Int. J. Miner. Process., 162, 36-47. DOI: 10.1016/j.minpro.2017.02.016.

Sastry K.V.S., Fuerstenu D.W., 1973. Mechanism of agglomerate growth in green palletization. Powder Technol., 7, 97-105.

Smirani-Khayati N., Falk V., Bardin-Monnier N., Marchal-Heussler L., 2009. Binder liquid distribution during granulation process and its relationship to granule size distribution. Powder Technol. 195, 105-112. DOI: 10.1016/j.powtec.2009.05.020.

Willett C.D., Adams M.J., Johnson S.A., Seville J.P.K., 2003. Effect of wetting hysteresis on pendular liquid bridges between rigid spheres. Powder Technol., 130, 63-71. DOI: 10.1016/S0032-5910(02)00235-8.

Received 20 October 2016

Received in revised form 23 May 2017

Accepted 10 June 2017 